\title{
Problems of Product Separation and Purification in Industrial Production of Phenol
}

\author{
V. M. Zakoshanskii \\ 4756 Doncaster Court, Long Grove, IL 60047-6929, USA \\ phone: (847)913-5861 \\ fax: (847)913-5872 \\ e-mail:vlazak@illallc.com,illa.ru@illallc.com,http://www.illallc.com
}

Received February 27, 2008

This article is withdrawn by the author, must be considered nonexistent and should not be cited. 